\title{
Carvalho Júnior, crítico literário e político
}

\author{
Carvalho Júnior, literary and political critic \\ THALES SANT'ANA FERREIRA MENDES ${ }^{1}$ \\ ${ }^{1}$ Universidade do Estado do Rio de Janeiro (UERJ). Rio de Janeiro, RJ, Brasil.
}

\begin{abstract}
Resumo: Pretendemos expor as ideias principais que norteiam a produção crítica de Carvalho Júnior. Relembrado pelos estudiosos como poeta de alguns poemas "carnais", o autor é extremamente desconhecido enquanto crítico literário e político; não obstante, contribuiu para a formação de uma crítica literária brasileira. Tomando como fonte o corpus recolhido por Arthur Barreiros (1879), este artigo funciona como uma introdução a essa produção de Carvalho Júnior. Assim, dividimo-lo em duas partes centrais: uma referente às suas concepções de literatura e de sistema literário, e outra sobre sua crítica literária e seu método crítico. Com isto, analisamos como o aporte estabelecido naquela influiu na prática desta. Demonstramos que a concepção de literatura do autor, alinhada a seus posicionamentos políticos, se baseia num ideal positivista, sobretudo taineano: haveria um vínculo estreito entre sociedade e produção artística, de forma que esta seria produto do meio e, juntamente com ele, evoluiria. Sua crítica literária, por outro lado, se pende para o Realismo-Naturalismo, parece nunca ter abandonado os sestros românticos, ou mesmo os clássicos, fazendo-o recorrer a Staël, Schlegel, Dumas filho e Aristóteles. É, por fim, uma crítica literária bem representativa do clima intelectual de 18701890, sobretudo no que diz respeito à confluência de estéticas literárias.
\end{abstract}

Palavras-chave: Francisco Antônio de Carvalho Júnior; crítica literária; século XIX.

\begin{abstract}
This paper aims at presenting the main ideas that constitute the critical production of Carvalho Júnior. The author, remembered by many scholars as the poet of some sensual poems, is entirely unknown as a literary and political critic. Nevertheless, he contributed to the formation of a Brazilian literary criticism. Thus, this paper works as an introduction to Carvalho Júnior's literary criticism, taking as a source the corpus collected by Arthur Barreiros (1879). For this purpose, we divided the paper in two central parts: one concerning his conceptions of literature and of literary system, and another about his literary criticism and his critical method. We analyse how the contribution established in that one influenced the practice of his criticism. We demonstrate that his conception of literature, attached to his political positions, was based on a positivist ideal: there would be a link between the society and its artistic production, so that the latter would be a product of the milieu and, along with it, would evolve. His literary criticism, on the other hand, although adept of the Realism-Naturalism, never excluded the romantic and even classic tendencies, making Carvalho Júnior turn to Staël, Schlegel, Dumas fils and Aristotle. Lastly, his literary criticism is representative of the 1870-1890 intelligentsia, mainly concerning the confluence of literary aesthetics.
\end{abstract}

Keywords: Francisco Antônio de Carvalho Júnior; literary criticism; $19^{\text {th }}$ century. 


\section{Um "poeta de raça"}

Ainda que de pouco vulto, a presença de Francisco Antônio de Carvalho Júnior (1855-1879) na historiografia literária brasileira tem certa constância. Sua única obra, Parisina, coligida postumamente em 1879 por Arthur Barreiros, foi suficiente - sobretudo devido aos 22 poemas enfeixados sob o título de "Hespérides" - para granjear a atenção de críticos de renome, como Antonio Candido, Massaud Moisés, Péricles Eugênio da Silva Ramos e Machado de Assis, este praticamente pioneiro na análise de tal obra. Hoje, decorrido mais de um século desde a publicação de Parisina, Carvalho Júnior ainda é comentado nos estudos de um ou outro pesquisador Gloria Carneiro do Amaral, José Américo Miranda e Vagner Camilo, por exemplo ${ }^{1}$ - como autor de uma poesia fortemente sensual, inserida no contexto de transição que marcou as letras brasileiras nas décadas de 1870 e 1880.

Se sua obra poética detém algum espaço no cenário dos estudos literários, o mesmo não se pode dizer de sua única peça teatral, homônima do volume de 1879 - a qual, nunca tendo sido encenada, foi razoavelmente comentada (principalmente seu prólogo) pela imprensa da época; e menos ainda de seus escritos sobre literatura e política, relegados ao esquecimento e à obscuridade. E, no entanto, Carvalho Júnior foi crítico literário e político; e, se não foi de raça, como disse

\footnotetext{
AMARAL, G. C. do. Aclimatando Baudelaire. São Paulo: Annablume, 1996; MIRANDA, J. A. O gerúndio e o luscofusco: som e sentido num poema de Carvalho Júnior. In: BASTOS, A. et al. Estudos de literatura brasileira. Belo Horizonte: Faculdade de Letras da UFMG, 2008; CAMILO, V. Erotismo e política: em torno de algumas figurações femininas na transição do romantismo ao realismo poético. Teresa: revista de literatura brasileira, São Paulo, n. 15, 2014.
}

Machado de Assis (1879, p. 384) sobre sua faceta de poeta, foi de certa valia. Pois, dentro da exiguidade e parcimônia de sua obra, contribuiu para a formação de uma crítica literária brasileira, se aproximando, ao mesmo tempo em que manteve feição própria, da produção de um Capistrano de Abreu, Sílvio Romero e Araripe Júnior.

A proposta deste artigo é ser uma espécie de introdução às principais ideias que percorrem as páginas de Carvalho Júnior. Com esse intuito, dividimo-lo em duas partes: uma referente às suas concepções de literatura e de sistema literário e outra propriamente sobre sua crítica literária, analisando como o aporte estabelecido naquela influiu na prática desta. Por fim, frisamos nossa restrição ao corpus recolhido por Barreiros, malgrado (como sugerem este e outros articulistas de então) a possibilidade de existência de outros ensaios esparsos por periódicos do século XIX, publicados sob pseudônimos ou mesmo anonimamente.

\section{A concepção de literatura}

Até onde nos consta, o estudioso que deu maior ênfase aos escritos críticos de Carvalho Júnior (depois de Barreiros) foi Massaud Moisés (2016, p. 174), ao observar a discrepância existente entre eles e o tom erótico da poesia do autor: "[...] parecia mais inclinado à poesia de feição política ou para o jornalismo de ideias" trajetória, afinal, de Lúcio de Mendonça, Afonso Celso, Fontoura Xavier e outros tantos homens de letras da mesma geração. Na vida pública, Carvalho Júnior foi, com efeito, um homem da política: bacharel em direito, promotor e superintendente do ensino de Angra dos Reis (RJ), além de juiz municipal de Botucatu (SP), colaborou em 
periódicos como A Republica (SP), Revista Academica de Sciencias e Lettras (PE) e A Reforma (RJ)².

Para repisar um clichê, foi, enfim, homem de seu tempo, cujos posicionamentos políticos (de um republicano liberal e abolicionista) perpassaram toda sua produção em prosa. É importante lembrar que "os jovens daquele tempo, no Brasil provinciano e atrasado", segundo Candido (2006, p. 31),"[...] eram agressivamente eróticos, com a mesma truculência com que eram republicanos e agrediam o Imperador, chegando alguns ao limiar do socialismo". Daí que, se considerados em conjunto, os escritos de Carvalho Júnior sobre literatura como que se inserem em um continuum, no qual é possível partir dos de menor teor político para aqueles cujos temas são totalmente políticos ("A liberdade de cultos", por exemplo). Tanto é assim que, ao apresentar o conteúdo de Parisina, Amaral (1996, p. 69) fala de "sete escritos críticos", e não quatro escritos críticos e três vários, conforme a divisão original de Barreiros.

Entusiasta das correntes em vigor nessa "época do 'materialismo'", que "assume ideologicamente as cores do evolucionismo darwinista, do liberalismo humanitário, do antiespiritualismo positivista" (STEGAGNOPICCHIO, 2004, p. 251), Carvalho Júnior compartilha em sua obra as premissas de um intelectual provavelmente treinado nas teorias de Comte, Taine, Buckle, Darwin e Spencer; mas sobretudo Taine, cujo influxo parece ter maior peso. Tanto no "Prefácio" a "Parisina", quanto no ensaio "O romance", o autor de "Hespérides" parte

\footnotetext{
2 Mantivemos a grafia original dos periódicos oitocentistas, tanto no corpo deste artigo quanto nas referências finais; a transcrição de seus conteúdos, no entanto, foi atualizada ortograficamente, assim como ocorreu com as citações dos escritos de Carvalho Júnior.
}

do pressuposto de que o meio social evolui: passa por etapas que vão superando umas às outras, participando de um processo de aprimoramento contínuo de suas ideias, de seus sistemas econômicos, políticos etc., que transforma as etapas anteriores em inviáveis, e até mesmo as destitui de uma "razão de ser". Falta injustificável seria repeti-las:

A escravidão foi um benefício, se a confrontarmos com o uso de matar os prisioneiros de guerra; o feudalismo justifica-se porque deve-se-lhe a origem das nacionalidades; o absolutismo foi um progresso porque aboliu as oligarquias; mas nenhuma dessas instituições pode ser aceita e pode vigorar no século XIX. (CARVALHO JUNIOR, 1879, p. 3).

A literatura, uma vez que tem feição "fatalmente determinada pelo meio social" (CARVALHO JUNIOR, 1879, p. 3), reflete, portanto, tal meio de origem e as ideias que Ihe são próprias; e, ao mesmo passo que ele, evolui. Como Capistrano de Abreu (1974 [1875], p.6) alegava por volta da mesma época, "a evolução, ou dissolução deste [o elemento literário] traduzem a evolução, ou dissolução daquele [o elemento social]". Ora, se nessa interrelação com o meio a literatura evolui, de modo que "cada época, cada civilização tem uma literatura" (CARVALHO JUNIOR, 1879 , p.4), é inevitável que certos estilos e formas literários se tornem antiquados: pecado em que Racine e Corneille incorreram, buscando adaptar a tragédia grega em pleno século XVII.

Também por isso, Paul et Virginie (1788), de Bernardin de Saint-Pierre, Atala (1801) e René (1802), de FrançoisRené de Chateaubriand, seriam romances impossíveis em meados do século XIX, sobretudo no que tange à evolução da 
figura da mulher. Afinal, "a civilização moderna, cultivando o espírito da mulher", reconhece "a necessidade de arrancá-la da treva e da ignorância a que tinha sido condenada pelos preconceitos do passado" (CARVALHO JUNIOR, 1879, p. 147); seriam, agora, inexequíveis aquelas heroínas idealizadas e lacrimosas. Por outro lado, os romances de George Sand, defensora dos "princípios da grande escola socialista", e os de Balzac, que "lançou as bases do realismo" (CARVALHO JUNIOR, 1879, p. 148), "acompanha[m] as evoluções do tempo", dando expressão às mudanças e revoluções sociais que ocorrem em seus respectivos meios.

Qual seu mestre francês, Carvalho Júnior pensa, portanto, em um vínculo estreito entre a sociedade e sua produção artística: sendo esta produto de seu meio, dele assimila, mas também transmite e reforça, os problemas, filosofias, fatos. Ideia próxima à de Capistrano de Abreu (1974, p. 6), que avaliava a literatura como "expressão da sociedade e a sociedade a resultante de ações e reações". São leis, afirma o autor carioca em "A evolução democrática", e leis inquebrantáveis e inevitáveis, assim como a evolução: "[...] a marcha da humanidade, impelida pelas leis fatais do progresso, é lenta e gradativa" (CARVALHO JUNIOR, 1879, p. 167). Há aí, porém, uma teleologia pouco demarcada em Taine, já que Carvalho Júnior entende as sucessões de literaturas (aqui, mais ou menos "estilos literários") como uma forma de evolução, isto é, de um constante aprimoramento em direção a um estágio mais elevado, que aniquila o sentido da existência das literaturas anteriores. Sem muitas dificuldades, pode-se concluir qual era, para ele, a fase superior da literatura brasileira.
No entanto, ao contrário dos românticos, e mesmo da geração posterior (pense-se em Sílvio Romero e Araripe Júnior, por exemplo), Carvalho Júnior não raciocina propriamente em termos de uma singularidade da literatura brasileira; ao menos em "A morgadinha de Val-Flor", entende que "[...] nós somos os herdeiros desse mísero patrimônio [português], em que pese a todos os otimistas que sustentam a existência de uma literatura nacional"; e, sem peias, arremata: "o nosso teatro é o teatro português" (CARVALHO JUNIOR, 1879, p.152). É digno de nota que os autores que ele cita em seus escritos, [que funcionam como] exemplos e meios de embasamento para suas asserções, são, em massa, franceses ou ingleses. Ainda assim, a ideia de uma tradição brasileira (ou luso-brasileira) não é algo que rejeite.

No "Prefácio", por exemplo, assinala sua "boa vontade" em seu "trabalho em prol das letras pátrias" (CARVALHO JUNIOR, 1879, p.9). Em "Fervet opus" (incluído em "Folhetins"), alega terem todas as nações "uma legião sagrada, a quem são confiadas as gloriosas tradições da pátria" (CARVALHO JUNIOR, 1879, p.137), isto é, a mocidade acadêmica e culta. A equação proposta é que evolução literária-intelectual pressupõe tradição. É nesse sentido que enaltece alguns dos poetas imortalizados pela historiografia literária brasileira, justamente aqueles reputados por ela como participantes de uma "tradição": Álvares de Azevedo, "a luminosa cabeça", Fagundes Varela, "O sabiá brasileu", Castro Alves, "o peregrino do ideal" (CARVALHO JUNIOR, 1879, p.137-8); contudo, também menciona nomes hoje desconhecidos: "Martim Cabral, a palavra mugida, Oliveira Belo, o 
orador inspirado" (CARVALHO JUNIOR, 1879, p.138).

Claro que, dentro da lógica positivista em que raciocina, tais homens de letras constituíram apenas um passo de toda uma escala progressiva da literatura. Não obraram a partir do nada, tal como não o fariam seus herdeiros. Afinal, "quando o caráter nacional e as circunstâncias envolventes operam, não o fazem sobre uma tabula rasa, mas sobre uma superfície, onde já se fizeram marcas" (TAINE, 2011 [1863], p. 537). É à mocidade que é delegada, então, a incumbência de continuar o legado desse "passado que morreu" (CARVALHO JUNIOR, 1879, p.138), a esses jovens que se valem da pena, da tribuna e da imprensa para debater "todos os princípios da filosofia, da arte, da religião, do direito, da ciência enfim" (CARVALHO JUNIOR, 1879, p.140). Nada mais adequado, portanto, chamar ao período uma "renascença" que será a expressão de Afrânio Coutinho (1974) para nomear os mesmos decênios de 1870-1890.

A ideia de uma "renascença" é retomada em outros momentos. Trespassa, inclusive, a concepção carvalhina de literatura. Pois se, como vimos, o autor a entende como reflexo das ideias de seu meio (ou da sociedade que a produz), a literatura da segunda metade do século XIX deveria ter, por natureza, feição científica, positivista, democrática. Afinal, no século XIX, época de um fervilhar intelectual, "os problemas políticos, sociais, morais, religiosos, científicos são geralmente investigados e a sua solução é a preocupação constante dos espíritos" (CARVALHO JUNIOR, 1879, p. 4). Se Taine (2011, p. 543) defendia a "utilidade" da literatura de ser um documento cujo ofício é "registrar sentimentos" e representar "a maneira de ser de toda uma nação e de todo um século", Carvalho Júnior (1879, p. 5) afirma que ela "apresenta um não sei quê de científico, de positivo, de prático, de utilitário, enfim".

A frase crucial para esse momento, repetida e glosada por ele em seus escritos, é "difusão dos conhecimentos pelas massas". Por ser essa feição tão característica do século XIX, a literatura que nele fosse produzida, caso não a traduzisse "fatalmente", "mentiria ao seu meio" (CARVALHO JUNIOR, 1879, p. 149). Desse modo, uma vez que o meio se constitui de "ideias práticas e utilitárias", de uma popularização do saber, de uma "sede inextinguível de verdade" (CARVALHO JUNIOR, 1879, p.149), o romance e o drama (os gêneros abordados, respectivamente, em "O romance" e no "Prefácio") se imbuem, forçosamente, de um caráter didático, e até "socialista": aquele é "o mais poderoso veículo de educação do povo" (CARVALHO JUNIOR, 1879, p. 146), e este, "uma escola" (CARVALHO JUNIOR, 1879, p. 6), de que Dumas filho é o exemplo máximo. A função da literatura é, ao fim, expor as verdades científicas de seu tempo às multidões, unindo o útil ao agradável.

Nisto o drama e o romance se diferenciam sutilmente. O primeiro tem maior apelo emocional, seu "ensino proveitoso [...] propaga-se de um modo fácil e deleitável" (CARVALHO JUNIOR, 1879, p.5), além de deter maior popularidade: "dirige-se universalmente às multidões", que "escutam, sentem e aprendem" (CARVALHO JUNIOR, 1879, p.5) (não é despropositadamente que Carvalho Júnior cita Suplício de uma mulher, "o drama arquétipo"). O romance, por outro lado, 
estando presente nos mais variados tipos de ambiente - "manuseiam-no o proletário e a cocote" (CARVALHO JUNIOR, 1879, p. 149) -, tem maior poder democrático e revolucionário, além de maior adaptabilidade ao meio; nele, o leitor encontra "um reflexo de seus próprios pensamentos" (CARVALHO JUNIOR, 1879, p. 149-150), uma fotografia de sua época. Com o drama, a verdade é recebida de modo mais sensorial e veemente; com o romance, mais duradoura e refletidamente. Em suma: com Carvalho Júnior teórico, a vitória vai para o romance; entretanto, em sua produção crítica e ficcional (veremos adiante), é o drama que desfraldará sua bandeira.

Ora, se a literatura transmite uma "verdade", cabe perguntar qual a natureza desta. Quase um naturalista brasileiro avant la lettre, Carvalho Júnior (1879, p.5) equaciona que o "belo funde-se na verdade"; "verdade" corresponderia ao mundo material. Tanto que, em seguida, endossa a indispensável fidelidade ao real, que é contraposto ao "ideal": "os tipos, os caracteres devem ser fiéis. O drama tem por objetivo a vida real". Daí que argumente (em 1877): “o espetáculo do vício não é imoral; quando muito é repugnante; o que é imoral é a sua impunidade" - e utiliza, para tanto, a metáfora científica do médico, que, "para extirpar os cancros, precisa vê-los" (CARVALHO JUNIOR, 1879, p. 6).

Recorde-se que seria o mesmo argumento empregado, anos mais tarde, por alguns escritores pós-românticos contra as alegações de indecência, e até de "pornografia", em suas obras; ou seja, a ideia de uma intenção didática do Realismo-Naturalismo, tão perpetuada pela historiografia literária dos séculos XIX e XX. E, antes de tudo, por autores de tais escolas: "sou contra a libidinagem literária, e não perdoaria nunca o escritor que me viesse, por amor do escândalo, descrever cenas imorais, episódios eróticos a título de naturalismo", palavras de Adolfo Caminha (1895, p.81-2). E Eça de Queiroz (1887, p. 2): o Realismo-Naturalismo pinta "cruamente e sinceramente o feio e o mau [da sociedade], não podendo, na sua santa missão de verdade, ocultar detalhe nenhum por mais torpe".

El Far (2004) mostra que retratações como as supracitadas não impediam que, no final das contas, obras realistas e naturalistas fossem vendidas e lidas por muitos como pornografia. O Apostolo, Jornal do Commercio e Jornal do Brasil, dentre outros periódicos, julgavam o argumento do didatismo uma falácia, quando não uma afronta à inteligência alheia (MENDES, 2018). No caso de Carvalho Júnior, vale citar a revisão de um articulista do Diário de S. Paulo, declarando ser "Parisina" - que versa sobre um caso de adultério e incesto - "imoral e perigoso", e que "ao drama falham completamente os intuitos morais" 3 . Curiosamente, Carvalho Júnior não apenas compartilhou uma sina semelhante, como foi constantemente reputado escritor realista: primeiro por si próprio; depois, por Barreiros (1879, p. IX), que chamou a atenção para a "excelência da escola realista" do autor; por Machado de Assis (1879, p.378), que destacou a "bandeira hasteada" do realismo; e por Sílvio Romero (1954 [1888], p.1806), ao notar seu "realismo mais cru". Péricles Eugênio da Silva Ramos (2004), no século

\footnotetext{
Gazetilha. Diario de S. Paulo, São Paulo, ano XIII, n. 3.552, 20 de outubro de 1877. O articulista insinua, quanto ao drama, a ausência de punição e de ensinamento que fossem adequados aos vícios ali expostos - ironicamente, o que Carvalho Júnior dizia abominar.
} 
seguinte, o classificaria, junto a Teófilo Dias, como cultor de uma "poesia realista". No plano teórico, porém, o foco na determinação do meio punha-o próximo à cartilha naturalista.

Da tríade taineana, é o meio (grafado por ele sempre em itálico) que ocupa o lugar central como "ordem de causas" da literatura, "que nada mais é do que um reflexo da sua economia" (CARVALHO JUNIOR, 1879, p.4) - asserção que, indo um pouco além de seu mestre, já tangencia ao socialismo, como então se dizia. A inevitabilidade do meio é tão grande que chega a afirmar: "é bem natural que, se o autor de Dom Juan escrevesse hoje esse poema [Parisina], tivesse o mesmo intuito que eu tive escrevendo este drama" (CARVALHO JUNIOR, 1879, p.6, grifos nossos) - e por intuito se entenda "estudar", "determinar causas" "deduzir ilações", enfim, dar-lhe "o cunho realista" (CARVALHO JUNIOR, 1879, p. 3). Noutras palavras, posto no meio social da segunda metade do Oitocentos, seria bem provável que Byron se tornasse escritor realista e adotasse método semelhante. Barreiros (1879, p.X) diferencia a peça justamente por haver nela o imperativo de que "o filósofo a fundamentasse", além de ecos do Zola de La curée; no poema byroniano, há apenas o canto do poeta, "sem curar das causas" (BARREIROS, 1879, p.X).

Já raça é termo de que se vale uma única vez, em "A morgadinha de Val-Flor", mencionando, em citação indireta de Schlegel, a "mesma raça" e "mesma civilização" (CARVALHO JUNIOR, 1879, p. 151) de Portugal e Espanha que geraram teatros tão diferentes. No folhetim "Aspásia", na esteira de Madame de Staël (2011 [1800], p. 81) e suas "literaturas do norte e do meio-dia", contrasta o nascido "sob um céu de fogo", cujos "afetos de [...] alma têm a imensidade dessa cordiIheira dos Andes" e "a impetuosidade de [...] rios caudalosos", cujo amor "é ardente e luxurioso" (CARVALHO JUNIOR, 1879 , p.112-3); e aqueles dos "gelos do norte, que têm a alma de neve e o coração envolto num sudário de brumas", cujo amor "é uma adoração, imaculada e pura" (CARVALHO JUNIOR, 1879, p.113), descendentes de Ossian. Perceba-se que as referências, nos casos citados, são românticas e, apesar dessas "linhas de cunho determinista" (AMARAL, 1996, p. 87), aludem menos às "disposições inatas e hereditárias" (TAINE, 2011, p. 535) de uma suposta raça do que a uma noção abrangente de "povo"; parecem, portanto, não ter a pesada carga cientificista que ganharam em Capistrano de Abreu ou em Sílvio Romero, mais afeitos a Comte, Buckle e Spencer.

Determinismo, fatalismo, evolucionismo: nesse repertório de ideias finisseculares, convivem, contudo, outras de dicção mais romântica, e até clássica. O mesmo prefácio que acende velas a Taine evoca, desembaraçadamente, Aristóteles. Num discurso de cautela com os preceitos naturalistas, Carvalho Júnior reconhece a dificuldade de conciliar a cientificidade e o "raciocínio rigoroso" em busca da verdade com a produção artística, afirmando ser aqueles prejudiciais a esta. Então procura solução no clássico: "nesse gênero de produção [o drama] a forma é quase tudo" (CARVALHO JUNIOR, 1879, p. 7), fazendo-se necessário manter "as três unidades do teatro grego, recomendadas por Aristóteles" (CARVALHO JUNIOR, 1879, p. 7). (O vocabulário, ao final do ensaio, será sobre "ordonnance", "urdimento das cenas" e "estrutura material".) Mas, em 
seguida, fundamentando-se em Schlegel, reavalia o argumento (a unidade de ação seria a verdadeiramente necessária) e, ao fim, comenta a possibilidade de harmonizar tais unidades com a "liberdade da inspiração poética" (CARVALHO JUNIOR, 1879 , p. 8). Em tempos de determinismo e explicações exteriores à literatura, Carvalho Júnior vinha chamar a atenção para a subjetividade e o formalismo da obra.

A forma pela qual o autor de "Hespérides" retoma o classicismo é, como ele mesmo sugere, a de um escritor que, em face das incertezas de sua inexperiência, busca nos velhos mestres uma direção segura para sua produção artística. Após as referências de autoridade de Aristóteles e Schlegel, é a vez do contemporâneo Dumas filho, em quem se apoia para justificar seu ponto de vista (que talvez ele próprio julgasse destoante para a época): no escritor francês, os "preceitos clássicos se acham consignados, o que dá um relevo apuradíssimo ao seu teatro" (CARVALHO JUNIOR, 1879, p. 8); há ainda Girardin, de cuja peça teria retirado as ideias gerais para a sua. Ao término, frisa sua homenagem ao realismo (Dumas filho e Girardin) e a Byron, pela apropriação do enredo do poema "Parisina".

Pela profusão de ideias dessemelhantes que conjugou, Carvalho Júnior parece de fato ter sido, conforme Ramos (2004) e Candido $(2006,2013)$ sugerem a propósito de sua poesia, um autor de transição (descontados, é claro, os ecos positivistas que a afirmação pode ter). Veja-se que a autonomia e a originalidade românticas de uma obra, a delimitação clássica da "criação" pela phýsis ou o determinismo naturalista do meio e da raça sobre o sujeito, implicações que acabam entrando em jogo ao se adotar esta ou aquela pers- pectiva filosófica e literária, não são estendidas em seus escritos a ponto de se tornarem conflitantes entre si. Sérgio Buarque de Holanda (2016, p.273) denunciava, entre os brasileiros, "a facilidade com que se alimentam, ao mesmo tempo, de doutrinas dos mais variados matizes e [...] [d]as convicções mais díspares. [...] A contradição que porventura possa existir entre elas parece-lhes tão pouco chocante". Por outro lado, pode-se pensar que justamente por serem trabalhadas num nível mais superficial e abrangente é que as ideias advogadas por Carvalho Júnior são possíveis; não sendo propriedades de épocas ou pessoas, mas participando de um fluxo de ressignificações (ao que, ironicamente, Carvalho Júnior era contra), são tratadas de forma a não se anularem, mas antes intentando-se extrair-lhes a "verdade".

Dados seus instrumentos de análise, resta saber com quais deles Carvalho Júnior construiu sua crítica literária.

\section{O método crítico}

Ao todo, Parisina reúne quatro críticas dedicadas a obras literárias, homônimas das tais obras que abordam: os dramas "A estátua de carne", do italiano Theobaldo Ciconi, "A morgadinha de Val-Flor", do português Pinheiro Chagas, e "O marido da douda", do gaúcho Carlos Ferreira todos eles (a julgar por suas repercussões nos periódicos) famosos na época. Há, ainda, a análise do livro de poemas "Ardentias", de Castro Rebelo Júnior.

A primeira crítica, curiosamente, se encontra na parte de "Folhetins", ao lado dos contos de Carvalho Júnior. A autoria da peça não é indicada, tampouco consta que o escrito trate de uma peça: com um 
estilo impressionista que vai sumarizando o enredo e as personagens, hoje poderia passar, a princípio, por outro conto. É de supor, no entanto, que a confusão não fosse feita pelo leitor da época, já que, durante a década de 1870, A estátua de carne era volta e meia anunciada e glosada em vários jornais do Rio de Janeiro, São Paulo e Pernambuco.

Pelo que se depreende do resumo grandiloquente de Carvalho Júnior, sua trama é algo romântica: certo dia, o conde Paulo de Santa Rosa, que gasta sua fortuna com jogos, bebidas e mulheres, se apaixona por uma costureira pobre, Maria, para quem omite sua posição; ela, doente, frágil e desgastada pelo trabalho, morre em pouco tempo. Meses depois, num baile, o conde conhece Noêmia Heller, cuja compleição é idêntica à da falecida. Outro, entretanto, é seu espírito: "sua moral é o prazer; a crápula e a devassidão" (CARVALHO JUNIOR, 1879, p. 126). Embevecido pela ressurreição da imagem da amada, o conde se entrega a Noêmia, que, devido ao posterior desprezo daquele, se "redimirá" antes de morrer.

A leitura que Carvalho Júnior faz da peça tem seu quê de moralista. Na descrição das atividades do conde Paulo, fala-se de um "desgraçado" em meio a "orgias" e "barregãs", que tem "sentimentos sopitados pela sensualidade, pelo gozo estúpido da matéria" (CARVALHO JUNIOR, 1879, p.124-5). Se Maria, já pelo nome, é a encarnação da pureza e da simplicidade, "cheia de virtudes" (CARVALHO JUNIOR, 1879 , p. 124), Noêmia, por outro lado, participa do imaginário literário do século XIX (sobretudo francês), em que a prostituta, ou a mulher livre que é vista como tal, é remida de sua vida impura na morte (LADENSON, 2016): ela é a “[...] nova
Magdalena, purificada no caudal do amor" (CARVALHO JUNIOR, 1879, p. 127).

Após a sinopse das qualidades morais das personagens, vêm as impressões da peça em si. Entre os encômios às interpretações dos atores (pois é de encômios que vive parte razoável de sua crítica), Carvalho Júnior (1879, p. 128) destaca a da artista Ismênia, que foi "fielmente executada segundo as leis da arte e da ciência". "Arte", cremos, tem aqui ecos helênicos, significando "técnica", correlacionada a um saber específico. Apesar do uso da palavra "ciência", o ideal ainda não parece ser cientificista, pois, adiante, o autor ressalta: "tudo, absolutamente tudo, a grande atriz exprimiu mais do que com arte e correção, com inspiração, que não é resultado do estudo, mas privilégio do gênio" (CARVALHO JUNIOR, 1879, p. 129, grifos nossos). $\mathrm{O}$ inatismo do gênio supera, assim, a ciência ou a técnica cultivada.

Eugênio de Magalhães, atuando como conde de Santa Rosa, "soube interpretá-lo com toda a verdade" (CARVALHO JUNIOR, 1879, p.129). A atuação teria sido, aliás, perfeita a ponto de corrigir a criação de Ciconi: "lutando com as incoerências e sutilezas daquele aborto da imaginação do escritor italiano, [o sr. Magalhães] soube contudo torná-lo verossímil" (CARVALHO JUNIOR, 1879, p.129). Isto é, sendo a peça não tão bem composta e inapta para alcançar a verossimilhança ${ }^{4}$, foi necessário que o gênio do ator, no virtuosismo de sua

\footnotetext{
4 Para "Stenio" (1875, p. 2), d'A Provincia (PE), "o drama, seja dito de passagem, peca e não pouco pela forma". Ora, A consciencia (SP) informa que o nome de Carvalho Júnior " $[. .$.$] se traduz nas lides da imprensa escolástica do$ Recife pelo festejado pseudônimo de Stenio" (MARINO, 1876 , p. 3). Conforme os fatos que apuramos de sua vida, o autor estava, com efeito, em Pernambuco por esse tempo; ademais, percebem-se, em ambos os ensaios, semelhanças de estilo e o compartilhamento de passagens em comum. É plausível, portanto, que o artigo d'A Provincia seja de sua autoria.
} 
performance, emendasse o mito do autor. Não parece ser outro o entendimento de Carvalho Júnior, que ao cabo do ensaio exalta o trabalho dos atores, os quais dão "corpo e realidade" às "personagens imaginárias sonhadas pelos poetas no remanso dos gabinetes" (CARVALHO JUNIOR, 1879, p.130), cujas execuções "sabem dar realidade", concretude, aos "filhos do ideal" (CARVALHO JUNIOR, 1879, p. 130).

A preocupação com a execução só é reiterada em "A morgadinha de Val-Flor", ao recriminar "a falta de movimento, de virilidade nas expressões" da obra, que "cansa, mortifica o espectador" (CARVALHO JUNIOR, 1879, p.155-6), embora isto se deva, para ele, mais à pena do autor do que à atuação em si. A crítica à verossimilhança, todavia, permanece. A peça de Pinheiro Chagas é acoimada de ser "pouco original na concepção, falsa nos caracteres e imperfeita na estrutura" (CARVALHO JUNIOR, 1879 , p.152). "Pouco original" porque, diz, o projeto da peça e de seus caracteres foi tomado de The Lady of Lyons (1838), de Bulwer-Lytton - e não de $O$ romance dum rapaz pobre, de Feuillet, como se pensava então, segundo Barreiros (1879, p.XIV).

O ensaio começa por defender a existência de tradições literárias (dramáticas) na França, Espanha e Alemanha e assinalar a falta de uma em Portugal, que "estava predestinado para a esterilidade" (CARVALHO JUNIOR, 1879, p. 151)5; e vai se desenvolvendo sob um lema de se "procurar sempre a verossimilhança

\footnotetext{
É curioso que, se Pinheiro Chagas (2017 [1867], p. 179) alegava,num escrito dedicado a Iracema, que "não se pode dizer que o Brasil possua uma literatura", Carvalho Júnior vem dizer, no ensaio dedicado ao escritor lusitano, justamente o mesmo de Portugal - embora, como mostramos, encare a literatura brasileira como nada mais do que uma literatura ainda portuguesa.
}

e a necessidade" (ARISTÓTELES, 1984, p. 254). Como que se fundamentando na Poética (sobretudo a parte XV), Carvalho Júnior julga incoerentes os caracteres de Luiz Fernandes e Leonor: ele, por suas ações e pensamentos que não se harmonizam; ela, por sua constituição intelectual, anacrônica para uma mulher do século XVIII: "incompatibilizou-a com os tempos que a viram nascer, com os costumes de sua época" (CARVALHO JUNIOR, 1879, p. 154). Ele sofre "um fim bem ridículo" (CARVALHO JUNIOR, 1879, p. 154), ela é "uma criatura ideal" que "nem existe hoje", que foge à verdade, ao real; ambos são "esplêndidos croquis" (CARVALHO JUNIOR, 1879, p. 154), inverossímeis.

A morte de Luiz Fernandes, comparada ao seu modelo, padeceria, ainda, de dois problemas em sua composição. Primeiro, seria incoerente com o mito e os caracteres, já que o final de Bulwer-Lytton é "mais compatível com a nobreza dos sentimentos e com o critério do personagem" (CARVALHO JUNIOR, 1879, p.153); em segundo, seria incoerente externamente, pois o desenlace do escritor inglês é "mais moral", "mais exemplar e mais proveitoso para a sociedade" (CARVALHO JUNIOR, 1879, p.153). Sem contar o erro acidental (em termos aristotélicos) de Pinheiro Chagas por ter falseado o cenário português setecentista; e, ainda, seu estilo excessivo e fastidioso, prejudicial à unidade de ação. "Situações há", recomenda Carvalho Júnior (1879, p. 155), "em que as falas devem ser concisas, lacônicas, incisivas, para produzir o efeito dramático" - descritivo e prescritivo, como o mestre grego. Mas o exemplo ideal é, outra vez, Dumas filho.

Essa convergência de orientações estético-filosóficas diversas que observamos em suas ideias sobre literatura parecem ganhar 
maior expressividade em sua crítica. Nesse sentido, é curioso o caso de "Ardentias (Carta ao amigo Castro Rebelo Júnior)". Rebelo Júnior, sabe-se, pertenceu à mesma geração do autor, época da "Batalha do Parnaso", da "poesia científica" de Martins Júnior e quejandos e, sobretudo, época de embate (ou, muitas vezes, amálgama) entre os resíduos românticos e a "Ideia Nova" (uma das alcunhas para o "Realismo") a ponto de Castello (2004) chamá-la de "falsa ruptura", e Stegagno-Picchio (2004), de "realismo romântico". É Castello (2004, p. 290) quem frisa que Rebelo Júnior, em Pseudo-Realismo: Sátira (1882?), comunga (como Carvalho Júnior) com Zola, Dumas filho, Feuillet etc., mas também com Casimiro de Abreu, Álvares de Azevedo e outros.

O Rebelo Júnior analisado por Carvalho Júnior é, todavia, ainda romântico. Românticas são também as notas que o autor traça de "Ardentias", identificando os possíveis modelos (Lamartine, Hugo, Musset, Varela e Castro Alves) do amigo e seu "fogo da imaginação" (CARVALHO JUNIOR, 1879, p.158). Os sestros da escola permeiam o impressionismo de suas descrições sobretudo quando ele exalta, em defesa das acusações de excesso contra Rebelo Júnior, a (livre) imaginação, "dote essencial a todo poeta" (CARVALHO JUNIOR, 1879, p.159), e a fantasia, que "corre livremente o mundo da ideia - o infinito" (CARVALHO JUNIOR, 1879, p.159).Carvalho Júnior (1879, p.157) também menciona seus versos "cheios de mimo e de encantos, possantes inspirações", e a idealização da mulher como um anjo em alguns dos poemas. Há até espaço para a correlação da obra com os sentimentos de seu criador - "as tuas Ardentias [...] são como que pedaços da tua alma de moço" (CARVALHO JUNIOR, 1879, p.159) -, bem como para a incompreensibilidade do artista pela crítica.

E dentro desse universo romântico, vem se destacar seu senso já um tanto parnasiano ao admirar a "facilidade do metro" do amigo e notar: "não encontrei um verso sensivelmente duro. És irrepreensível na forma" (CARVALHO JUNIOR, 1879, p. 158) - algo cuja relevância aumenta quando se lembra da inclusão de Carvalho Júnior em antologias de poesia parnasiana. Ressaltemos também o fato de não deixar passar (malgrado o discurso laudatório) que um poema de Rebelo Júnior, similar a outro de Vacquerie, tenha "o defeito de não ser original" (CARVALHO JUNIOR, 1879, p.158), e que certas composições suas, embora de alguma beleza, contenham "imagens que não são perfeitamente originais" (CARVALHO JUNIOR, 1879, p. 159).

A necessidade de adequação da literatura às ideias de seu tempo e a fatalidade da evolução (a lógica da superação) esposadas por Carvalho Júnior talvez expliquem sua quase obsessão pela "originalidade" das obras que analisa, muito embora isso também possa ser interpretado à luz das noções românticas de criação e individualidade da obra. Barreiros (1879, p. IX) pôs à prova "Parisina", salientando que originalidade é o que "toda a composição deve ter de primário", levando em conta, para isso, que "os objetos e os indivíduos são sempre os mesmos" (BARREIROS, 1879 , p.X), mudam apenas os pontos de vista. Aliás, um dos motivos de elogio de Carvalho Júnior a "O marido da douda (fragmento)" deve-se justamente por ser "uma peça original" (CARVALHO JUNIOR, 1879, p.163).

É neste escrito que, juntamente com "A morgadinha...", Carvalho Júnior nos 
apresenta uma crítica mais bem organizada - infelizmente, também é, dos quatro, o único incompleto. Procuramos mostrar que, se a bibliografia positivista e de estirpe semelhante perfazem muitas das ideias de Carvalho Júnior, seu método crítico, em contrapartida, não chegou a ser o de um Taine ou o de um Saint-Beuve; se muito, o de um Hennequin ou o de um Lanson, autores que provavelmente não leu. Nele não há espaço para o biografismo (exceto, talvez, a insinuação apontada em Ardentias), para questionários sobre a vida e os hábitos dos autores ou para a determinação da influência do meio e da raça na obra. Viu-se que em "A morgadinha..." há, pelo contrário, o arremate "clássico" de que "o drama é, sem rodeios, mal construído" (CARVALHO JUNIOR, 1879, p. 154).

"O marido da douda" lança mão de um repertório mais positivista do que o das outras críticas: retorna à ideia de uma literatura brasileira em formação, rumo a uma caracterização própria, de modo que a peça represente um "esforço individual em prol das letras pátrias", o que já seria oportuno mesmo se ela "não tivesse nenhuma valia intrínseca" (CARVALHO JUNIOR, 1879, p.163). Além disso, não deixa dúvidas quanto à filiação literária da peça: é "vazada nos moldes do teatro moderníssimo" (CARVALHO JUNIOR, 1879, p. 162) - o que, segundo o "Prefácio" e "O romance", só pode se referir ao Realismo. Aliás, como um romance naturalista, o drama ainda orbitaria ao redor de uma tese.

Mas que tese? De acordo com um articulista do Publicador Maranhense, "a tese escolhida [...] é que a mulher muitas vezes desvaria-se e cai, por culpa de errada educação que recebeu e que deixou desenvolverem-se n'alma os germens do mal, e, por consequência, ao esposo ultrajado não cabe o direito de matar a adúltera"6. Outra vez o didatismo realistanaturalista; e outra vez, não faltou quem a ele se opusesse: para um redator $\mathrm{d}^{\prime} \mathrm{O}$ Apostolo, sua "urdidura é imoral" e o "valor moral do drama [...] é nenhum"7. Carvalho Júnior chega a defender não a tese em si (ao menos, não no que restou da crítica $^{8}$ ), mas o direito de se valer de uma em um drama. Se no "Prefácio" havia uma circunspecção frente ao cientificismo na literatura (mormente a dramática), aqui há mesmo uma defesa. Em face do comentário de um crítico de que "a tese era mais assunto de uma dissertação de medicina legal do que de um drama" (CARVALHO JUNIOR, 1879, p. 163), o autor de "Parisina" rebatia, numa postura sintonizada com "O romance" e o "Prefácio", que "as teses psicológicas tem tanto o direito de ser discutidas no teatro, como as sociais, morais e quaisquer outras" (CARVALHO JUNIOR, 1869, p. 163).

A formulação de Carvalho Júnior quanto à tese se extraviou. $\mathrm{O}$ último parágrafo de "O marido da douda" reconhece a recorrência do tema do adultério na literatura, e cuida haver diversas causas, consequências e soluções para tal, como as já lançadas por Dumas Filho. O próprio autor teria desenvolvido algumas delas em "Parisina". A seu modo, enviesado pelo pensamento de sua época, Carvalho Júnior se posicionou nos escritos em prosa a favor da liberação da mulher quanto a certos preconceitos sociais e em prol de maior

\footnotetext{
Noticiario. Publicador Maranhense, Maranhão, ano XXXVI, n. 242, p. 2, 21 de outubro de 1877.

Correspondencia do Apostolo. O apostolo, Rio de Janeiro, ano XII, n. 63, p. 3, 2 de junho de 1878.

8 E, por outro lado, o autor não faz nenhuma crítica negativa a Carlos Ferreira, e ainda apresenta um panorama biobibliográfico do escritor gaúcho.
} 
participação dela na sociedade; portanto, é possível que não chegasse à mesma conclusão do Publicador Maranhense. Barreiros (1879), por sua vez, vislumbrou uma interpretação coerente de "Parisina" em que a figura de Alexandre, o marido traído, seria uma sátira, propositalmente caricata. Afinal, Davina, a adúltera, que expressa com clareza os motivos de sua infidelidade, permanece livre e viva ao fim da peça - legando-nos, hoje, possibilidades de leituras.

\section{Um "crítico de raça"?}

Muito embora Carvalho Júnior tenha ficado para a posteridade como o autor de alguns poemas "carnais" (cinco, quando muito), também atuou, conforme procuramos atestar, de maneira bem interessante enquanto crítico literário e político. Com esta faceta, pôde contribuir para a formação de uma crítica literária brasileira, representativa de muitos dos ideais esposados por intelectuais de 1870-1890.

E porque era um dos membros mais participantes dessa geração, foi, como ela, fervoroso defensor da abolição da escravatura, da proclamação da república e de todo o aparato cientificista e positivista que excitava os ânimos dos jovens de então - ao mesmo tempo em que bebia em fontes de resquícios românticos, dando razão à crítica de Machado de Assis (1879, p.374), para quem alguns dos poetas da "nova geração" ainda cheiravam ao "puro leite romântico".

Portanto, como a maioria de seus Colegas de ideologia, não foi completamente "realista". Sua concepção de literatura, que se misturava a seus posicionamentos políticos, estava baseada num ideal positivista: defendia a existência de um vínculo estreito entre sociedade e produção artística; defendia a influência do meio sobre ambas, defendia sua constante evolução. Porém, a lei fatal (adjetivo que foi tão caro aos adeptos dessa perspectiva) do progresso, que afetaria literatura e política, diferentemente da de Taine, teria preponderância do "meio", pouca do "momento" e nenhuma da "raça". Postura, ao fim, mais adequada, que pôde fazê-lo se posicionar contra os preconceitos relacionados à mulher e à intolerância religiosa, além de afastá-lo do "biografismo" e de certos determinismos.

Se sua crítica literária procurou seguir achados realistas (que, afinal, era o nome que ele e seus coevos faziam de égide para sua batalha antirromântica), também não chegou a abandonar de fato a herança romântica (segundo pretendia a maioria), ou mesmo a deixar de lado certos preceitos clássicos, com o que recorreu a Staël, Schlegel, Dumas filho e Aristóteles. $\mathrm{Na}$ verdade, seu método crítico acabou perseguindo ideais como o de originalidade e verossimilhança, além de se atentar para os aspectos formais das obras. Em tudo isto, não se afastou do tom geral de sua época; e se algum pecado cometeu, foi o de ter escrito pouco.

\section{Referências}

AMARAL, G. C. do. Aclimatando Baudelaire. São Paulo: Annablume, 1996.

ARISTÓTELES. Poética. Tradução, comentários e índices de Eudoro de Souza. São Paulo: Abril Cultural, 1984.

ASSIS, J. M. M. de. A nova geração. Revista brazileira: jornal de sciencias, lettras e artes, Rio de Janeiro, tomo II, p. 373-413, out.-dez.1879.

BARREIROS, A. Carvalho Junior. In: CARVALHO JUNIOR, F. A. de. Parisina. Prefácio de Arthur Barreiros. Rio de Janeiro: Typ. Agostinho Gonçalves Guimarães, 1879. 
CAMINHA, A. Cartas litterarias. Rio de Janeiro: Typ. Aldina, 1895.

CANDIDO, A. Os primeiros baudelairianos. In: CANDIDO, A. A educação pela noite e outros escritos. Rio de Janeiro: Ouro sobre Azul, 2006.

CANDIDO, A. Formação da literatura brasileira: momentos decisivos (1750-1870). 14. ed. Rio de Janeiro: Ouro sobre Azul, 2013.

CAPISTRANO DE ABREU, J. A literatura brasileira contemporânea [1875]. In: COUTINHO, A. Caminhos do pensamento crítico. Rio de Janeiro: Americana; Prolivro, 1974. Vol. II. p. 5-30.

CARVAlHO JUNIOR, F. A. de. Parisina. Prefácio de Arthur Barreiros. Rio de Janeiro: Typ. Agostinho Gonçalves Guimarães, 1879.

CASTELLO, J. A. A Literatura Brasileira: origens e unidade (1500-1960). São Paulo: Editora da Universidade de São Paulo, 2004.

CHAGAS, M. J. P. Literatura brasileira: José d'Alencar. In: SOUZA, R. A. de. Na aurora da literatura brasileira: olhares portugueses e estrangeiros sobre o cânone literário nacional em formação (18051885). Rio de Janeiro: Caetés, 2017. p. 179-187.

COUTINHO, A. Caminhos do pensamento crítico. Rio de Janeiro: Americana; Prolivro, 1974. Vol. II.

EL FAR, A. Páginas de sensação: literatura popular e pornográfica no Rio de Janeiro (1870-1924). São Paulo: Companhia das Letras, 2004.

HOLANDA, S. B. de. Raízes do Brasil. Ed. crítica. São Paulo: Companhia das Letras, 2016.

LADENSON, E. Literature and sex. In: LYONS, J. (Ed.). The Cambridge Companion to French Literature. Cambridge: Cambridge University Press, 2016. p. 222-240.

MARINO. Correspondencia. A consciencia: fiat lux, São Paulo, ano 1, n. 6, p. 3, 15 de julho de 1876.

MENDES, L. Zola as pornographic point of reference in late nineteenth-century Brazil. Excavatio, Albertina, v. 30, 2018.
MOISÉS, M. História da literatura brasileira. Vol. II: Do Realismo à Belle Époque. 3. ed. São Paulo: Cultrix, 2016.

QUEIROZ, J. M. E. de. Prefacio dos "Azulejos". A Semana, Rio de Janeiro, ano III, v. III, n. 120, 16 abr. 1887.

RAMOS, P. E. da S. A renovação parnasiana na poesia. In: COUTINHO, A. (Org.). A literatura no Brasil. Vol. IV: Era realista, era de transição. 7. ed. São Paulo: Global, 2004. p. 91-149.

ROMERO, S. História da literatura brasileira. 5. ed. Rio de Janeiro: J. Olympio, 1954. Tomo Quinto. (Coleção Documentos Brasileiros, 24-d).

STAËL, M.me de. Sobre as literaturas do norte e do meio-dia [1800]. In: SOUZA, R. A. de (Org.). Uma ideia moderna de literatura: textos seminais para os estudos literários (1688-1922). Chapecó: Argos, 2011.

STEGAGNO-PICCHIO, L. História da literatura brasileira. 2. ed. Rio de Janeiro: Nova Aguilar, 2004.

STENIO. A estatua de carne. A provincia: orgao do partido liberal, Recife, ano IV, n. 693, p. 2, 30 set. 1875

TAINE, H. Prefácio [à História da literatura inglesa] [1863]. In: SOUZA, R. A. de (Org.). Uma ideia moderna de literatura: textos seminais para os estudos literários (1688-1922). Chapecó: Argos, 2011.

Recebido em: 18 de novembro de 2018

Aceito em: 16 de dezembro de 2018

Thales SANT'ANA FERREIRA MENDES

Licenciado em Letras - Português/Inglês/Literaturas pela Universidade Federal Rural do Rio de Janeiro. Mestrando em Literatura Brasileira pela Universidade do Estado do Rio de Janeiro (UERJ), com pesquisa sobre F. A. de Carvalho Júnior, sob orientaçao do Prof. Dr. Roberto Acízelo Q. de Souza.

(D) http://orcid.org/0000-0003-2306-013X

<thales.sanfer@hotmail.com> 